\title{
Categorization of directional motion verbs
}

\author{
Jacek Waliński
}

University of Łódź, Poland

\begin{abstract}
This study presents a proposal of categorization of directional motion verbs, i.e. ones whose lexical semantics specifies a direction of motion, even without an overt directional complementation. The categorization proposed here includes (1) source/goal verbs, which are used to refer to bounded paths; (2) unbounded path verbs, which can be divided into two subgroups of upward/downward verbs and forward/backward verbs; (3) route verbs, which include cross and pass; (4) constant verbs, which again can be divided into two subgroups of chase verbs and accompany verbs; (5) deictic verbs, namely come and go, which are approached as a separate class. The proposal originates from previous studies conducted to this end in semantics, and is meant to encourage discussion on further advancement in this area of linguistic studies.
\end{abstract}

Key words: categorization, motion events, motion verbs, lexical semantics, directionality

\section{Introduction}

Every language has a system of semantic devices used to encode motion as a basic aspect of human experience. The idea of the primacy of movement in apprehension of the surrounding reality can be traced back to Aristotle's insight that motion is the fundamental principle of nature: "Nature is a principle of motion and change ... We must therefore see that we understand what motion is; for if it were unknown, nature too would be unknown." (Aristotle, 350BC/1995, Physics, pp. 200b11-14). According to this view, to understand the nature of the world we must understand the dynamic nature of surrounding events, by which we come to understand the sensible form of imperceptible, immaterial concepts, such as inside-outside, new-old, close-distant, etc., arising from consequential relationships (see Sheets-Johnstone, 2011 for a discussion on how movement serves as the foundation of our knowledge of the world).

In his Principles of Philosophy, Descartes proposes to define motion as "simply the action by which a body travels from one place to another" (Descartes, 
1644/1985, Part II, 24). Descartes (1644/1985, Part II) argues that, in one sense, motion can be interpreted as "change of place", which is relative to an arbitrary reference body (Principles, Part II, 13). Another sense of motion is "the ordinary sense" (Principles, Part II, 24), which stems from the rules of ordinary speech, in which motion is attributed to bodies whose movement is caused by some action, without reference to a change of location. For instance, a person sitting motionless on board of a ship which is leaving port is said to be at rest in the ordinary sense, because he/she performs no action. However, from the relative perspective, the person is in motion because at each point during the departure the person gets farther away from the shore.

This distinction, systematized in linguistics by Tesnière (1959/2015, pp. 311-313), allows for a disassociation of dislocation from movement, which provides the conceptual ground for distinguishing two basic classes of motion verbs. One includes the verbs whose lexical semantics conflates a path of motion between one place and another, which implies directionality. The other class includes the verbs whose lexical semantics conflates the manner of movement understood as a dynamic activity which does not entail a change of location. This distinction has been regarded as a basic dividing line between verbs of motion in all major approaches to their lexical semantics. This study presents a proposal of categorization of directional motion verbs, i.e. ones whose lexical semantics specifies a direction of motion, even without an overt directional complementation (Jackendoff, 1983; Levin, 1993; Talmy, 1985, 2000). The proposal originates from previous studies conducted to this end in semantics (Geuder \& Weisgerber, 2008; Rappaport Hovav \& Levin, 2010; Zwarts, 2008), and is meant to serve as a springboard for further advancement in this area, especially in corpus-based linguistic studies.

\section{Basic semantics of motion}

A basic conceptualization of an object in motion, without regard to the characteristics of the object or the details of the trajectory it follows, is PATH, which was put by Lakoff (1987, p. 267) among basic kinesthetic image schemas (cf. Jackendoff, 1983, Ch. 9). Lakoff (1987) points out that the basic experience of motion can be described more thoroughly with a SOURCE-PATH-GOAL schema, which reflects that "Every time we move anywhere there is a place we start from, a place we wind up at, a sequence of contiguous locations connecting the starting and ending points, and a direction" (Lakoff, 1987, p. 275). This image schema includes four structural elements: (1) a SOURCE, i.e. the starting point; (2) a GOAL, 
i.e. the ending point, (3) a PATH, i.e. a sequence of contiguous locations connecting the source and the goal; (4) a DIRECTION going toward the destination.

Lakoff \& Núñez (2000, pp. 37-38) add that the basic structure of the SOURCEPATH-GOAL image schema manifests an inherent logic used in mathematics and geometry to discuss, for example, lines "meeting at a point" or to describe the graph of a function as "reaching a minimum at zero". However, they distinguish a broader set of elements expanding beyond this basic schema: (1) a trajector that moves; (2) a source location; (3) a goal, i.e. an intended destination of the trajector; (4) a route from the source to the goal; (5) the actual trajectory of motion; (6) the position of the trajector at a given time; (7) the direction of the trajector at that time; (8) the actual final location of the trajector (which may or may not be the intended destination).

Talmy $(1985,2000$, p. 25) sketches a prototypical motion event as the situation that "consists of one object (Figure) moving or located with respect to another object (the reference object or Ground)". The basic schema of Motion event has four core components, which apart from the above-mentioned Figure and Ground, include also Motion and Path. The Path is a path followed or site occupied by the Figure object with respect to the Ground. The component of Motion "refers to the presence per se of motion or locatedness in the event" (Talmy, 2000, p. 25), despite the fact the component in the latter motion as such does not occur. Talmy (2000, pp. 35-36) distinguishes two types of motion found in motion events: translational motion, in which "an object's basic location shifts from one point to another in space"; and self-contained motion, in which "an object keeps its same, or 'average' location", e.g. oscillation, rotation, expansion, contraction, etc., or rest.

Moreover, Talmy $(1985,2000$, p. 26) distinguishes an associated Coevent: "a motion event can be associated with an external Co-event that most often bears the relation of Manner or of Cause to it". Thus, besides the abovementioned four internal components of the core schema of motion, the Manner component reflects the manner in which the motion takes place, and the Cause is the cause of its occurrence. Talmy (1985, pp. 139-140) explains that the assessment of whether Manner or Cause is conflated in a verb depends on the verb's basic reference to what the Figure does or to what the Agent/Instrument does. For instance, "Tom pushed the keg" expresses Cause because the verb refers to what the Agent (Tom) did. On the other hand "Tom rolled the keg" expresses Manner since the verb basically refers to what the Figure (keg) did.

Mani and Pustejovsky (2012), following largely Talmy's (1985, 2000, Part 1) work on motion semantics, assume that spatial expressions of motion can be decomposed into distinct semantic elements, which include: (a) the event of MOTION; (b) the FIGURE that is undergoing movement; (c) the PATH or the region 
traversed; (d) the GROUND against which the movement occurs; (e) the MANNER of movement; (f) the MEDIUM involved. Apart from these semantic components, Mani and Pustejovsky (2012) see argument structure, semantic role selection, and event structure as essential aspects of meaning required for the representation of lexical information about motion (see Carlson, 1984; Gruber, 1976). The semantic components of movement are encoded in various ways using different lexicalization patterns.

\section{Lexicalization patterns of motion events}

By examining the systematic relations between different aspects of meaning and surface forms of linguistic expression across languages, Talmy $(1985,1991,2000)$ demonstrates how the semantic structure of linguistic representations reflects the conceptual structure in the domain of motion. Linguistic elements taken into consideration include open class categories, such as verbs of motion, and closed class categories, such as prepositions acting as satellites. The satellite is defined by Talmy (2000, p. 102) as "the grammatical category of any constituent other than noun-phrase or prepositional-phrase complement that are in a sister relation to the verb root", e.g. move away, move behind, move between, move up, etc.

Talmy $(1985,2000$, Part 1) observes that different languages conflate the semantic components of the Motion event in different ways. He identifies main typological patterns of the mappings between the meaning and form for the expression of motion events. The Motion +Co-event pattern (Talmy, 2000, pp. 27-29) can be illustrated with the sentences such as "The rock rolled down the hill" (Motion+Manner), or "The napkin blew off the table" (Motion+Cause). It is characteristic of the Indo-European family except Romance languages, as well as Finno-Ugric, Chinese, and others. The Motion+Path pattern (Talmy, 2000, pp. 49-53) can be illustrated with the following sentences from Spanish: "La botella entró a la cueva (flotando)" [Lit. The bottle MOVED-in to the cave (floating), i.e. "The bottle floated into the cave"], and "La botella salió a la cueva (flotando)" [Lit. The bottle MOVED-out to the cave (floating), i.e. "The bottle floated out of the cave"]. This pattern is characteristic of Romance and Semitic families of languages, as well as Japanese, Korean, Polynesian, Turkish, and others.

On the basis of the patterns used for mapping the semantic components of the core schema (particularly Path) and co-events (Manner and Cause) onto the surface forms, Talmy (1991, 2000, Part 1) proposes to distinguish two main categories of languages. The languages that characteristically map the core schema into the verb are referred to as Verb-framed languages (V-languages). 
They tend to conflate Motion+Path in verbs, while a co-event of Manner or Cause is typically encoded with adverbials and gerunds, or just left to inference. The languages that characteristically map the core schema onto the satellite are referred to as Satellite-framed languages (S-languages). Generally, S-languages, including English, tend to conflate Motion+Manner in verb roots whereas the Path is encoded with satellites and prepositional phrases.

Filipović (2007) demonstrates how studying lexicalization patterns provides insights into how speakers of different languages from the same group organize experiential data in their accounts of events. By comparing two S-languages, English and Serbo-Croatian, she demonstrates that speakers of these two languages use two different algorithms for the processing of sentences expressing motion events. More recent studies (e.g. Beavers, Levin, \& Wei Tham, 2010; Sampaio, Sinha, \& Sinha, 2009) suggest elaboration of Talmy's classification to include additional language types. Despite such criticisms, Talmy's typological framework still stands as a valid contribution to our understanding of the processes of form-meaning connections for the expression of motion events in cross-linguistic contexts (see Goschler \& Stefanowitsch, 2013 for an edited collection of studies).

\section{Directional verbs of motion}

In a series of publications, Levin and Rappaport Hovav (1992, 2013; Rappaport Hovav \& Levin, 2010) argue for the hypothesis that verb meanings can be systematically categorized as manner or result, with directionality counting as the result for motion verbs. They assume that a core meaning of a verb contains a single semantic component of manner or result, which they term manner/ result complementarity. As a result of the complementary distribution, a given verb should be classified as either a manner verb or as a result verb, but not both (Rappaport Hovav \& Levin, 2010, p. 22). However, the discussion on semantic role restrictions in the syntax-semantics interface goes back, at least, to Chomsky's (1981, p. 36) theta-criterion (see Jackendoff, 1985).

According to Levin and Rappaport Hovav (2013, 2014; Rappaport Hovav \& Levin, 2010), what is essential for this distinction to hold is that lexicalized meaning, i.e. a verb's core meaning, must be distinguished from contextual meaning. "Crucially, a verb's lexicalized meaning is to be distinguished from additional facets of meaning that can be inferred from a particular use of that verb in context and from the choice of noun phrases serving as arguments of the verb" (Levin \& Rappaport Hovav, 2013, p. 49). Due to conventions of carrying out certain actions, a verb tends to be associated with a variety of co-occurring 
properties. Some verbs, such as sweep, lexicalize manners, but may be used to talk about events that are often associated with prototypical results (see implied fulfillment verbs in Talmy, 2000, pp. 265-267). In a parallel fashion, verbs such as leave lexicalize direction, but may be used to talk about results brought about in a conventionally associated manner. Levin and Rappaport Hovav (2014, p. 339) emphasize that not all these co-occurring properties are lexically entailed by the meaning of the verb itself and may not hold of every use of the verb (see Goldberg, 2010 for a criticism).

In order to provide a semantic explication for the notions of manner and result, Rappaport Hovav \& Levin (2006, 2010, pp. 28-33) propose that the directed motion verbs do not have to be telic, however, they must specify scalar changes. A scale is a set of degrees or points ordered on a particular dimension. The dimension represents an attribute of an argument of the verb and the degrees indicate the possible values of the attribute. A scalar change involves a change in the value of one of scalar-valued attributes. With directed motion verbs, the scale is composed of a set of contiguous points that together constitute the path of motion. The path extends in a particular direction, which defines the ordering relation.

In English, the directed motion verbs can be subdivided according to the way the ordering relation is defined. In one type of verbs, including ascend, descend, fall, and rise, the direction of motion is fully lexicalized by the verb with reference to the pull of gravity. With verbs come and go, the direction of motion is determined deictically according to whether they get closer to or further on the path from the deictic centre. In another type of motion verbs, which includes advance, arrive, depart, enter, exit, leave, reach, recede, and return, the direction is determined with respect to an external reference object, the semantic ground. Depending on the meaning of individual verbs, the points on the path are ordered according to whether they are closer to or further away from this object.

Rappaport Hovav \& Levin (2010, p. 30) add that the claim that the directed motion verbs are scalar finds support in the structure of their scales. They essentially fall into two classes: those associated with two-point scales and those associated with multiple-point scales (see Beavers, 2008). Two-point scales have only two values, i.e. they basically encode having or not having a particular property. The directed motion verbs with an associated two-point scale are arrive, depart, enter, and exit. On the other hand, multiple-point scales have many values. The class of directed motion verbs with multiple-point scales is used to describe gradual traversals of the path. It includes advance, descend, fall, recede, and rise. The multiple-point scales can again be divided into two types: those with closed scales and those with open scales. In the directed motion domain, this property distinguishes between verbs that lexicalize a bounded path, such as come and return, and verbs that lexicalize an unbounded path, such as descend and rise (see Rappaport Hovav \& Levin, 2010 for further discussion). 
Levin and Rappaport Hovav (2013) analyze in detail certain English verbs that apparently violate the manner/result complementarity. In the domain of motion, a widely discussed counterexample to manner/result as two separate roots is the English verb climb (e.g. Fillmore, 1982, p. 32; Jackendoff, 1985). One may assume that in sentences such as "John climbed the tree", the verb expresses both manner (clambering) and direction (upward). However, with reference to animate entities the opposite direction can be specified, e.g. "John climbed down the mountain", which shows that the verb can be used to lexicalize only the manner of motion. Moreover, with reference to inanimate entities, the verb is used only to lexicalize the direction upward, e.g. "The elevator/temperature climbed", but not downward, e.g.? "The elevator/temperature climbed down", which indicates that the verb can be used to lexicalize only the direction of motion. Levin and Rappaport Hovav (2013) argue that once the interpretation of different uses is clearly delineated, it becomes clear that the verb climb manifests a certain degree of polysemy, having both manner and result senses. The upward direction is usually inferred due to the default direction of its lexicalized manner.

In her earlier work on English Verb Classes and Alternations, Levin (1993) discusses directional verbs of motion under the label of verbs of inherently directed motion. She includes the following verbs in this class: advance, arrive, ascend, climb, come, cross, depart, descend, enter, escape, exit, fall, flee, go, leave, plunge, recede, return, rise, and tumble. She notes that some verbs included in the list, most notably climb and cross, diverge in some respects from the other members of this class (Levin, 1993, p. 264). She points out that meaning of the verbs of inherently directed motion specifies the direction of motion, even in the absence of an overt directional complement. While for some verbs in this class the specification of direction is deictic, for others it is specified in non-deictic terms. Levin emphasizes that none of the verbs in this class specifies the manner of motion. They differ as to how they can express the goal, source, or path of motion. Depending on the given verb, these properties may be expressed via a prepositional phrase, as a direct object, or both (Levin, 1993, p. 264).

Apart from this generic class, Levin distinguishes additionally three more specific classes of verbs related to directionality. The class of leave verbs (Levin, 1993, Ch. 51.2) includes: abandon, desert, and leave. The verbs in this class indicate motion away from a location without specifying the manner of motion. Because the direct object of these verbs indicates the location that has been left, it cannot be expressed in the prepositional phrase (Levin, 1993, p. 264). The class of chase verbs (Levin, 1993, Ch. 51.6) includes: chase, follow, pursue, shadow, tail, track, and trail. These verbs are typically transitive, with the chaser as subject and the person being chased as object. Some of them allow an intransitive use, with the chaser as subject and a prepositional phrase headed by after specifying the object 
of pursuit (Levin, 1993, p. 270). The class of accompany verbs (Levin, 1993, Ch. 51.7) includes: accompany, conduct, escort, guide, lead, and shepherd. They relate to one person taking another person from one place to another. These verbs can be differentiated from one another by the relation holding between the two participants (Levin, 1993, p. 270).

Starting from the observation that direction plays an important role in the semantics of both prepositions and verbs, Zwarts (2008) suggests broad parallels between the realizations of directionality in these parts of speech. After distinguishing two major categories of locative and directional prepositions, he follows Jackendoff (1983) to point out that directional prepositions largely correspond to Paths. With reference to spatial and aspectual dimensions expressed by prepositions in spatial expressions, Zwarts (2008, p. 84) proposes to distinguish seven classes of directional prepositions. (1) Source prepositions impose a locative condition on the initial part of the path, e.g. from; (2) Goal prepositions indicate the opposite pattern, putting emphasis on the final part of the path, e.g. into; (3) Route prepositions impose a locative condition on a middle part of the path, e.g. past, through, across, and over; (4) Comparative prepositions involve a spatial ordering of the extremes of the path, with towards referring to paths that have their endpoint closer to the reference object than their starting point, and away from referring to paths going further and further away from the starting point; (5) Constant prepositions impose a stable locative condition on all the points of the path, e.g. through or along; (6) Geometric prepositions typically involve a circular path enclosing an object on all sides, although the relation is not always so simple, e.g. around; (7) Periodic prepositions refer to a repeating pattern, e.g. around and around, up and down, through and through, etc. Zwarts suggests that the characteristics of paths can be extended to the semantics of dynamic verbs, giving a partial typology of "event shapes" as places and paths in the conceptual space of events.

Geuder \& Weisgerber (2008) propose to divide verbs of motion specifying a particular trajectory or contour in a way parallel to directional prepositions. Their proposal allows to distinguish the following types of directional verbs of motion:

(1) Goal verbs relate to the end point on the path of motion, e.g. enter, arrive; (2) Source verbs relate to the starting point on the path of motion, e.g. exit, depart; (3) Route verbs relate to intermediate points on the path of motion, e.g. cross and pass; (4) Comparative verbs relate to movement closer to/further from a reference object, e.g. approach; (5) Constant verbs relate to the same average relation of distance between objects in motion, e.g. follow, (6) Holistic verbs describe a geometric shape of the described motion, e.g. curl; (7) Periodic verbs describe a recurring pattern in the described motion, e.g. zigzag. Please note that in English the holistic and periodic verbs appear to belong to the category of manner, rather than directional verbs of motion. 


\section{Categorization of directional verbs of motion}

The categorization of motion verbs proposed in this paper is based on the abovereviewed classifications proposed by Geuder and Weisgerber (2008), Jackendoff (1983); Levin, (1993), Rappaport Hovav and Levin (2010), and Zwarts (2008), with the help of WordNet (Fellbaum, 2017) and VerbNet (Palmer, Bonial, \& Hwang, 2017).

The first group of directional motion verbs distinguished here includes source/goal verbs, understood as scalar verbs associated with a two-point scale (Rappaport Hovav \& Levin, 2010). The meaning of these verbs inherently specifies the direction of motion, even in the absence of an overt directional complement (Levin, 1993, Ch. 51.1). They can be divided further into source verbs (depart, exit, leave) and goal verbs (arrive, enter, reach). They refer to bounded paths which focus, respectively, on the starting point or the destination of the path of motion (Fillmore, 1983; Geuder \& Weisgerber, 2008; Zwarts, 2008). Additionally, the verb return, which lexicalizes a bounded path whose goal goes back to the starting point, is also included in this group. These verbs indicate that motion from/to a location takes place without specifying the manner of motion. For these verbs the direction of motion is specified in non-deictic terms. Prototypical examples of these verbs in English include: arrive, depart, enter, exit, leave, reach, and return.

The second group of directional motion verbs includes unbounded path verbs, which lexicalize unbounded paths. They can be approached as scalar verbs with a multiple-point scale (Rappaport Hovav \& Levin, 2010). Prototypically, they refer to gradual traversals but do not specify the manner of motion, although climb is sometimes viewed as lexicalizing both manner and path (Fillmore, 1982, p. 32; Jackendoff, 1985; Levin \& Rappaport Hovav, 2013). These verbs can be divided into two subclasses. The first subclass refers to the vertical plane, indicating either the direction upward (ascend, climb, rise) or downward (descend, drop, fall, dive, plunge, tumble). These verbs specify the direction of motion in absolute terms, with or against the pull of gravity. Prototypical examples of these verbs in English are: ascend, climb, descend, dive, drop, fall, plunge, rise, and tumble. The other group of the unbounded path verbs distinguished here relates to a gradual extension on the horizontal plane. Their semantics specifies either the direction forward (advance, proceed) or backward (retreat, recede, withdraw). Additionally, the comparative verb approach, which refers to a spatial path extending towards a reference object (Geuder \& Weisgerber, 2008; Zwarts, 2008), is also included in this group. In contrast with the upward/downward verbs, for the forward/backward verbs, the direction of motion is specified in relative terms. Prototypical examples of these verbs in English include: advance, approach, proceed, retreat, recede, and withdraw. 
The third group of directional motion verbs proposed to be distinguished includes route verbs, namely cross and pass, which relate to intermediate points on the path of motion (Geuder \& Weisgerber, 2008; Jackendoff, 1983, p. 165; Zwarts, 2008). They tend to be ascribed to the category of directional motion verbs (e.g. Levin, 1993). However, as pointed out by Rappaport Hovav and Levin (2010, p. 30), they are not verbs of scalar change. Although they specify motion along a path defined by a particular axis, the direction of motion along the path is not lexicalized by the verb, i.e. they do not impose an ordering relation on the path. However, they are not manner verbs, either, which suggests that they belong to a separate group.

The fourth group of directional motion verbs that can be distinguished includes the verbs labeled by Geuder \& Weisgerber (2008) as constant verbs. They express an approximately stable spatial relation between two moving objects without specifying the manner of motion. They can be divided into two classes. The first subclass includes chase verbs (Levin, 1993, Ch. 51.6), which are typically transitive, with the chaser as the subject and the object of pursuit as the direct object. Prototypical examples of these verbs in English include: follow, pursue, shadow, tail, track, and trail. The other subclass of the constant verbs includes accompany verbs (Levin, 1993, Ch. 51.7). In actual motion expressions, they relate to one person accompanying another from place to place. They can be differentiated from one another by the nature of the relation between the two participants, but not by the manner of motion. Prototypical examples of these verbs in English include: accompany, conduct, convoy, escort, guide, lead, shepherd, and usher.

The final group of directional verbs proposed here includes deictic verbs. This term is usually applied in linguistics to a small set of verbs, whose interpretation relies on the location relative to participants of the communicative act. In English this set includes two motion verbs come and go. Interpreting deictic motion verbs involves perspective-taking, which differentiates them from other motion verbs. According to Talmy $(1985,2000)$, deictic motion verbs belong to Path-conflating verbs. He defines them in rather generic terms: "the deictic component of Path typically has only the two member notions 'toward the speaker' and 'in a direction other than the speaker'" (Talmy, 2000, p. 56).

The use of the deictic motion verbs has been a popular topic in linguistic studies. Fillmore $(1982,1983)$ demonstrates the complexity of coming and going in terms of the deictic parameters of person, place and time. He proposes a set of "appropriateness conditions" for the use of come and go in English. He points out that although their uses are largely overlapping, there is a certain area of uses in which only go is allowed, and a relatively more restricted area of uses in which only come can be used. Goddard (1997) analyzes the semantics of coming and going using the Natural Semantic Metalanguage (NSM) approach. His analysis essentially confirms that the lexical semantics of come and go are compatible with the appropriateness 
conditions proposed by Fillmore. Rauh (1981) demonstrates that in German, the deictic feature of the verbs kommen (come) and gehen (go) can be neutralized, if an expression contains an adverbial indicating the source/goal of movement. Wilkins and Hill (1995) question the assumption that come and go manifest a universal deictic opposition. They argue that what is universally recognized as go is not an inherently deictic expression. However, due to systemic opposition with come, it often takes on a deictic interpretation through pragmatic attribution.

\section{Conclusions}

A fully systematic classification of motion verbs has not been worked out in linguistics. One reason that stands behind this situation is the difficulty of discerning motion verbs as a separate class. Although Miller and Johnson-Laird (1976, pp. 526-531) suggest that English has a formally identifiable semantic field of motion verbs, they admit that the criteria available for distinguishing motion verbs generate numerous borderline cases and gray areas. On the basis of morphosyntactic considerations, Levin and Rappaport Hovav (1992) conclude that approaching motion verbs as constituting a single formally discernible natural class in English is a wrong assumption. The assumption that motion verbs are the "purest and most prototypical forms" of verbs (Miller \& Johnson-Laird, 1976, p. 527), implies that other verbs inherit some conceptual and formal properties from them, which makes conceptual/formal distinctions difficult to draw precisely (Wilkins \& Hill, 1995, p. 248).

The division proposed in this paper is an attempt to advance the categorization of directional motion verbs into a number of systematic classes. The proposal does not aspire to be fully exhaustive, but is meant to accumulate feedback and encourage further discussion. It was originally worked out for the purpose of studying directional motion verbs used in the expressions of fictive motion (Waliński, 2018). Since it served its original purpose reasonably well, it can hopefully be employed for other corpus-based studies on motion semantics.

\section{References}

Aristotle. (350BC/1995b). Physics [written c. 350BC]. In J. Barnes (ed.), The Complete Works of Aristotle (Vol. 1). Princeton, NJ: Princeton University Press.

Beavers, J. (2008). Scalar complexity and the structure of events. In J. Dölling, T. Heyde-Zybatow, \& M. Schäfer (eds.), Event Structures in Linguistic Form and Interpretation, (pp. 245-265). Berlin: Walter de Gruyter. 
Beavers, J., Levin, B., \& Wei Tham, S. (2010). The typology of motion expressions revisited. Journal of Linguistics, 46(02), 331-377. https://doi.org/10.1017/S0022226709990272

Carlson, G. N. (1984). Thematic roles and their role in semantic interpretation. Linguistics, 22(3), 259-280. https://doi.org/10.1515/ling.1984.22.3.259

Chomsky, N. (1981). Lectures on Government and Binding: The Pisa Lectures. Dordrecht: Foris.

Descartes, R. (1644/1985). Principles of Philosophy. In J. Cottingham, R. Stoothoff, \& D. Murdoch (trans.), The Philosophical Writings of Descartes, (pp. 177-292). Cambridge: Cambridge University Press.

Fellbaum, C. (2017). WordNet: An Electronic Lexical Resource. In S. E. F. Chipman (ed.), The Oxford Handbook of Cognitive Science, (pp. 301-314). Oxford: Oxford University Press.

Filipović, L. (2007). Talking About Motion: A Crosslinguistic Investigation of Lexicalization Patterns. Amsterdam: John Benjamins.

Fillmore, C. J. (1982). Towards a Descriptive Framework for Spatial Deixis. In R. J. Jarvella \& W. Klein (eds.), Speech, Place, and Action: Studies of Deixis and Related Topics, (pp. 31-59). New York: John Wiley.

Fillmore, C. J. (1983). How to know whether you're coming or going. In G. Rauh (ed.), Essays on Deixis, (pp. 219-227). Tübingen: Gunter Narr.

Geuder, W., \& Weisgerber, M. (2008). Manner of Movement and the Conceptualization of Force. Slides presented at the Journée d'étude "Il y a maniere et maniere," Université d'Artois, Arras.

Goddard, C. (1997). The semantics of coming and going. Pragmatics, 7(2), 147-162. https://doi. org/10.1075/prag.7.2.02god

Goldberg, A. E. (2010). Verbs, Constructions, and Semantic Frames. In M. Rappaport Hovav, E. Doron, \& I. Sichel (eds.), Lexical Semantics, Syntax, and Event Structure, (pp. 39-58). Oxford: Oxford University Press.

Goschler, J., \& Stefanowitsch, A. (eds.). (2013). Variation and Change in the Encoding of Motion Events. Amsterdam: John Benjamins.

Gruber, J. S. (1976). Lexical Structures in Syntax and Semantics. Amsterdam: North Holland.

Jackendoff, R. (1983). Semantics and Cognition. Cambridge, MA: MIT Press.

Jackendoff, R. (1985). Multiple subcategorization and the theta-criterion: The case of climb. Natural Language and Linguistic Theory, 3(3), 271-295. https://doi.org/10.1007/BF00154264

Lakoff, G. (1987). Women, Fire, and Dangerous Things: What Categories Reveal About the Mind. Chicago: University of Chicago Press.

Lakoff, G., \& Núñez, R. E. (2000). Where Mathematics Comes from: How the Embodied Mind Brings Mathematics into Being. New York: Basic Books.

Levin, B. (1993). English Verb Classes and Alternations: A Preliminary Investigation. Chicago: University of Chicago Press.

Levin, B., \& Rappaport Hovav, M. (1992). The lexical semantics of verbs of motion: The perspective from unaccusativity. In I. M. Roca (ed.), Thematic Structure. Berlin: De Gruyter.

Levin, B., \& Rappaport Hovav, M. (2013). Lexicalized Meaning and Manner/Result Complementarity. In B. Arsenijević, B. Gehrke, \& R. Marín (eds.), Studies in the Composition and Decomposition of Event Predicates, (pp. 49-70). Dordrecht: Springer. https://doi.org/10.1007/978-94-0075983-1 3

Mani, I., \& Pustejovsky, J. (2012). Interpreting Motion: Grounded Representations for Spatial Language. Oxford: Oxford University Press.

Miller, G. A., \& Johnson-Laird, P. N. (1976). Language and Perception. Cambridge, MA: Harvard University Press. 
Palmer, M., Bonial, C., \& Hwang, J. D. (2017). VerbNet: Capturing English Verb Behavior, Meaning, and Usage. In S. E. F. Chipman (ed.), The Oxford Handbook of Cognitive Science (pp. 315-336). Oxford: Oxford University Press.

Rappaport Hovav, M., \& Levin, B. (2010). Reflections on manner/result complementarity. In M. Rappaport Hovav, E. Doron, \& I. Sichel (eds.), Lexical Semantics, Syntax, and Event Structure, (pp. 21-38). Oxford: Oxford University Press.

Rauh, G. (1981). On coming and going in English and German. Poznań Studies in Contemporary Linguistics, 13, 53-68.

Sampaio, W., Sinha, C., \& Sinha, V. D. S. (2009). Mixing and mapping: Motion, path, and manner in Amondawa. In J. Guo, E. Lieven, N. Budwig, S. Ervin-Tripp, K. Nakamura, \& Ş. Özçalişkan (eds.), Crosslinguistic Approaches to the Psychology of Language: Research in the Tradition of Dan Isaac Slobin (pp. 427-439). New York: Psychology Press.

Sheets-Johnstone, M. (2011). The Primacy of Movement, Expanded 2nd Ed. Amsterdam: John Benjamins.

Talmy, L. (1985). Lexicalization patterns: Semantic structure in lexical forms. In T. Shopen (ed.), Language Typology and Syntactic Description, Vol. 3: Grammatical Categories and the Lexicon (pp. 57-149). Cambridge: Cambridge University Press.

Talmy, L. (1991). Path to Realization: A Typology of Event Conflation. In Proceedings of the Seventeenth Annual Meeting of the Berkeley Linguistics Society, (pp. 480-519). Berkeley, CA: Berkeley Linguistics Society.

Talmy, L. (2000). Toward a Cognitive Semantics, Vol. II: Typology and Process in Concept Structuring. Cambridge, MA: MIT Press.

Tesnière, L. (1959/2015). Elements of Structural Syntax [First published in 1959 as Éléments de syntaxe structurale]. (T. J. Osborne \& S. Kahane, trans.). Amsterdam: John Benjamins.

Waliński, J. T. (2018). Verbs in Fictive Motion. Łódź: Wydawnictwo Uniwersytetu Łódzkiego. https:// doi.org/10.18778/8142-382-3

Wilkins, D. P., \& Hill, D. (1995). When "go" means "come": Questioning the basicness of basic motion verbs. Cognitive Linguistics, 6(2-3), 209-260. https://doi.org/10.1515/cogl.1995.6.2-3.209

Zwarts, J. (2008). Aspects of a typology of direction. In S. D. Rothstein (ed.), Theoretical and Crosslinguistic Approaches to the Semantics of Aspect, (pp. 79-105). Amsterdam: John Benjamins. 